\title{
SIGNIFICADOS DA COPA DO MUNDO DE FUTEBOL: SENTIMENTOS E MANIFESTAÇÕES DOS TORCEDORES
}

\author{
Gabriel Leandro Silva, Renan Bernardino de Souza, Jaqueline Costa Castilho Moreira \\ Universidade Estadual Paulista - UNESP, Curso de Educação Física, Departamento de Educação Física, Campus de \\ Presidente Prudente. E-mail: gabrielsantos 1234@hotmail.com
}

\begin{abstract}
RESUMO
A Copa do Mundo de Futebol é uma tradicional competição de esporte único com 20 edições já realizadas. O objetivo deste trabalho foi investigar os significados da Copa do Mundo para os torcedores brasileiros, por meio de depoimentos de domínio público sobre os certames de 2002 e 2014. A metodologia envolveu uma pesquisa histórica, utilizando-se de métodos como levantamento em base de dados, bibliográfico e mapeamento de publicações online com esses depoimentos, disponíveis em sites esportivos, jornalísticos e de entretenimento. A interpretação dos dados foi feita através de análise de conteúdo. Esse estudo possibilitou investigar alguns dos sentimentos coletivos e atemporais, de emoção ou de comoção, que foram manifestados por torcedores brasileiros durante as Copas citadas. O torcer que une e identifica um grupo e a significação do jogo como drama vivenciado por uma sociedade foram outros elementos que afloraram das manifestações dos depoentes.
\end{abstract}

Palavras-chave: futebol, torcida, copa do mundo, emoção, dramatização.

\section{MEANINGS OF THE FOOTBALL WORLD CUP: FEELINGS AND MANIFESTATIONS OF FANS}

\begin{abstract}
The Football World Cup is a traditional single sport competition with 20 previous editions. The aim of this study was to investigate the significance of the World Cup for the Brazilian fans through public domain testimonials about the exhibitions of 2002 and 2014. The methodology involved a historical research, using methods such as survey in database, bibliographic and mapping of online publications with these statements, available at sporting sites, journalism and entertainment. Data interpretation was done through content analysis. This study made it possible to investigate some of the collective and timeless feelings of excitement or emotion, which were manifested by Brazilian fans during the aforementioned Cups. The twist that unites and identifies a group and the significance of the game as drama experienced by a society were other elements that surfaced of the manifestations of the deponents.
\end{abstract}

Keywords: football, fans, world cup, emotion, drama. 


\section{INTRODUÇÃO}

A Copa do Mundo de Futebol é uma tradicional competição de esporte único que teve seu início em 1930, no Uruguai. A exceção de 1942 e 1946, período em que as disputas foram suspensas em função da Segunda Guerra Mundial, o espetáculo foi retomado quadrienalmente sem mais interrupções (DUARTE, 1987; RIBAS, 2010; GEHRINGER, 2010; MARTINEZ, 2010).

Foram 20 edições realizadas o que tornou o evento, um fenômeno polissêmico com grande amplitude e repercussão internacional. Em sua multiplicidade de sentidos e significados, a realização da Copa do Mundo mobiliza embates econômicos e políticos, bem como questões sociais e culturais.

O país que sedia o acontecimento ganha não somente visibilidade midiática com a exposição de suas características territoriais e difusão de seus costumes, como também assume o comprometimento de desencadear ações determinadas à efetivação estrutural do evento, muitas vezes aproveitadas politicamente como metáfora de desenvolvimento do país-sede que recepciona as competições.

Para DaMatta(2003) a metáfora do capitalismo aparece e molda não somente as competições propriamente ditas, mas a organização das unidades que disputam esses certames.

Em outra escala, a Copa do Mundo desperta as mais variadas "significações" (BARFIELD, 2000) nos envolvidos, desde sentimentos relacionados ao pertencimento, interação, identidade coletiva, como também representações mentais, emoção e/ou comoção além de outros estados interiores por parte dos apreciadores do futebol e dos que possuem grande afeição por suas seleções nacionais.

Este estudo investiga duas edições da Copa do Mundo que evidenciaram o Brasil, resultando no estabelecimento da periodização descrita a seguir. A escolha pelo evento de 2002, realizada em continente asiático e simultaneamente em dois países Japão e Coréia do Sul, caracteriza a conquista inédita do pentacampeonato mundial e, a Copa de 2014 ocorrida em território brasileiro, pelo desfecho que causou grande comoção aos torcedores e visibilidade mundial, por ter sido a maior derrota brasileira, o placar mais negativo não só em Copas, como de toda a trajetória de seleções nacionais.

Assim, o objetivo deste trabalho foi investigar os significados da Copa do Mundo de futebol para os torcedores brasileiros, por meio de depoimentos de domínio público sobre os certames de 2002 e 2014.

\section{METODOLOGIA}

Considerando o objetivo do trabalho, optou-se por uma pesquisa histórica realizada a partir de fontes secundárias, de abordagem exploratória e descritiva, com análise qualitativa dos dados.

Esse mapeamento de publicações ocorreu com levantamento em base de dados acadêmicos (Scielo e Google Acadêmico) e bibliográfico. Desse último, emergiram autores como DUARTE (1987), RIBAS (2010), GEHRINGER (2010) e MARTINEZ (2010), que tratam a temática Copa do Mundo, em uma perspectiva jornalística.

Também foram pesquisados depoimentos de torcedores, extraídos de materiais já publicados e de domínio público, disponíveis em sites esportivos (GLOBO ESPORTE, BBC), jornalísticos (UOL, G1) e de entretenimento como o YOUTUBE, escolhido por possibilitar o acesso a opiniões e comentários audiovisuais desses entusiastas.

Para a recuperação desses dados foram usadas como indexadores (e/ou termos de busca), as palavras: "relatos", "depoimentos", "falas", "entrevista", "comentando", "comentário", "torcedor", "público", "pessoas", combinados com o operador booleano "E", dentro da periodização já mencionada: Copas do Mundo de 2002 e 2014 como forma de inclusão/exclusão 
de depoimentos dos torcedores. Vale ressaltar que somente foram escolhidas as locuções dos torcedores resultaram em duas a dez linhas de comentário.

Dessa forma, a amostra de depoimentos foi composta por vinte torcedores brasileiros, de ambos os gêneros, de cada evento, em um total de 40 opiniões online.

A interpretação dos dados foi feita através de análise de conteúdo (BARDIN, 2009). Tendo como o referencial teórico DaMatta $(1983,2003)$ e Sahlins (2006), a análise de conteúdo buscou encontrar nos interditos dos comentários publicados dos torcedores, o inconsciente coletivo a partir da apuração das locuções.

\section{RESULTADOS}

Ao articularmos os 40 depoimentos com o referencial teórico foram encontradas nove categorias de locuções, nomeadas de: crítica social, análise de jogo, memória, repercussão midiática, emoção, pertencimento, estratégia/tática, cultura e lazer. Destas será aprofundada a categoria emoção, por melhor expressar a significação da Copa pelos torcedores. Ainda dentro dessa categoria foi possível evidenciar outras subcategorias como: jogo como representação da sociedade, especificidades do futebol brasileiro, dramatização na narração do evento; das quais será enfocado apenas a questão da dramatização, pela exiguidade de páginas disponíveis.

A categoria emoção/dramatização foi sintetizada a partir dos comentários dos torcedores ao elencar seus sentimentos em relação às duas edições pesquisadas. Esses sentimentos percebidos conscientemente e suas manifestações objetivas expressas pelo "torcer por um time" são reconhecidas dentro da antropologia das emoções.

Para facilitar o entendimento da categoria emoção, as locuções dos torcedores encontradas nas Copas de 2002 e 2014 foram apresentadas na forma de quadros e embora os depoimentos sejam públicos e estejam publicados online nos Portais UOL (2002), BBC (2002), FOLHA (2002), YOUTUBE (2010); G1(2014), ESTADÃO(2014), DOMINGOS (2014), FRANCESCHINI; SOARES e ALMEIDA (2014), os nomes dos torcedores foram omitidos e indicados pela letra " $D$ " seguida de número para diferenciação.

O Quadro 1 apresenta depoimentos sobre a Copa de 2002, obedecendo os critérios de exclusão já mencionados. 
Quadro 01. "Categoria Síntese" Significado da Copa de 2002 para os torcedores brasileiros

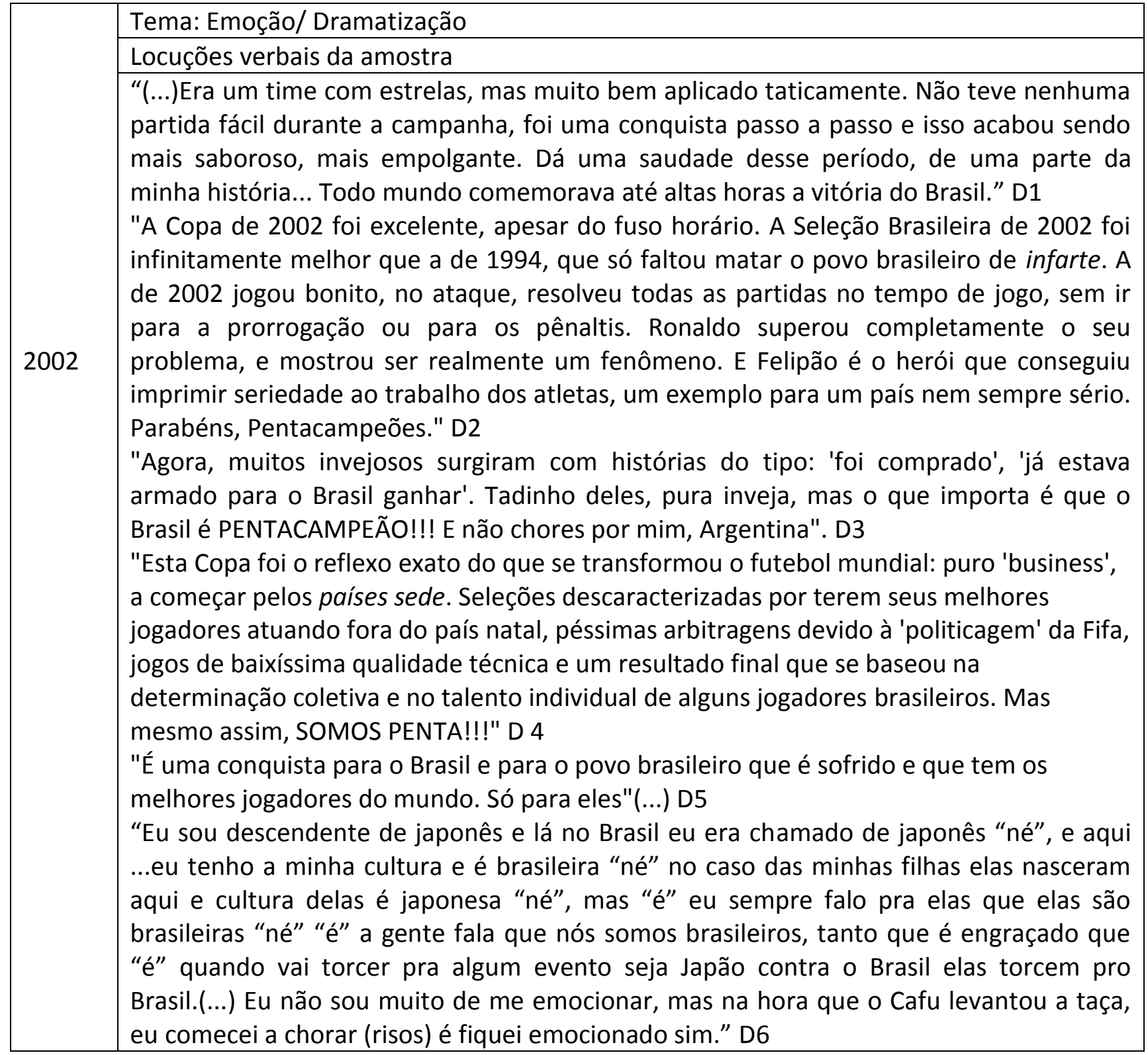

Fonte: Autoria própria.

A seguir será mostrado o Quadro 2 que contem os depoimentos de torcedores sobre a final da Copa de 2014. Importante ressaltar que também neste quadro foram feitas exclusões, conforme os critérios anteriormente citados. 
Quadro 02. Categoria-síntese "Significado da Copa de 2014 para os torcedores brasileiros"

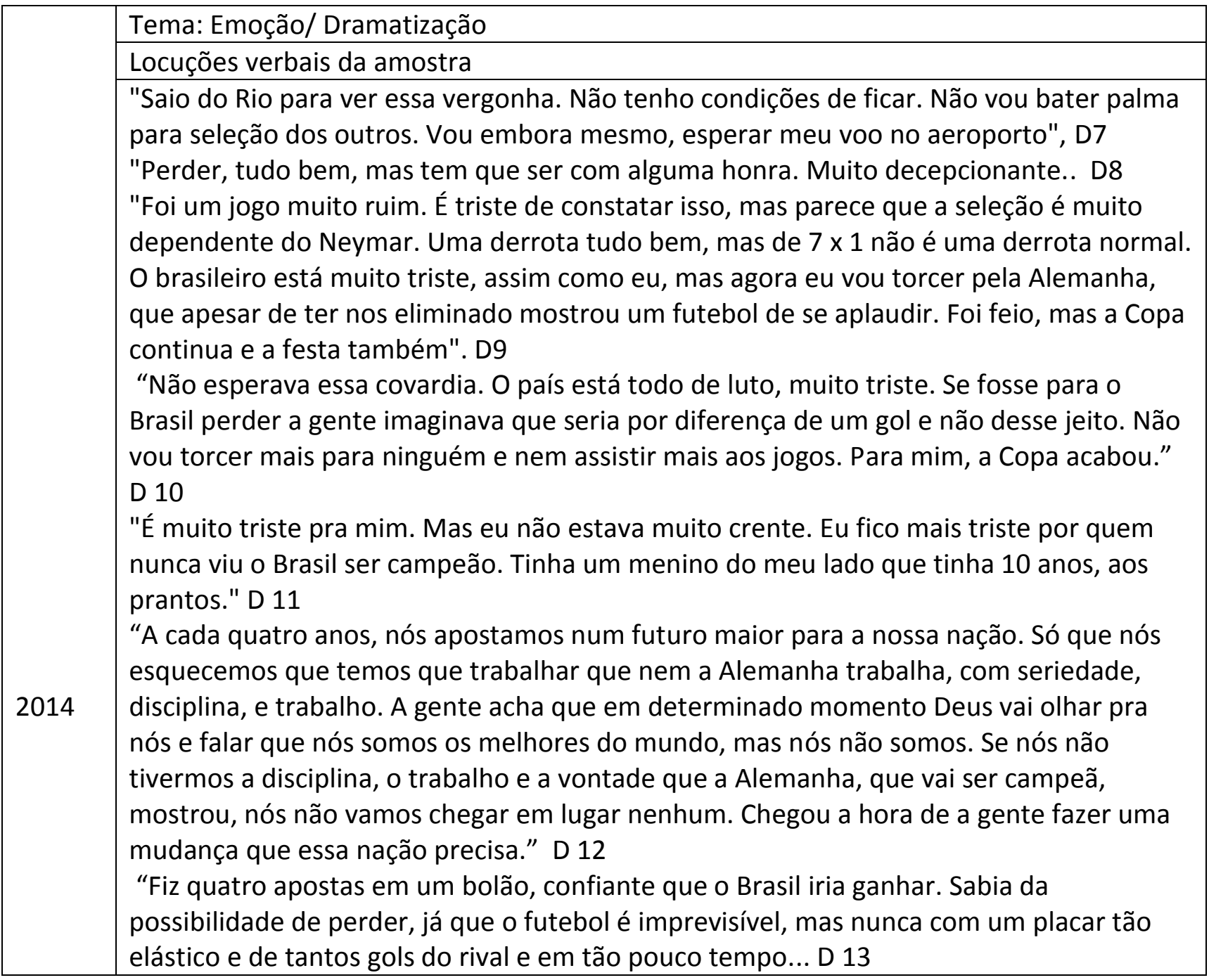

Fonte: Autoria própria

\section{DISCUSSÃO}

Analisando a primeira edição, o fato do time brasileiro ter sido pentacampeão gerou um sentimento de alegria e identidade. Este mesmo sentimento aconteceu em outros campeonatos, sendo citado na poesia "O momento feliz" de Carlos Drummond de Andrade (2014) ao se remeter a copa de 1970:

(...) De repente o Brasil ficou unido contente de existir, trocando a morte o ódio, a pobreza, a doença, o atraso triste por um momento puro de grandeza e afirmação no esporte. Vencer com honra e graça com beleza e humildade é ser maduro e merecer a vida, ato de criação, ato de amor(...)

O afloramento de sentimentos com características atemporais e coletivas como as citadas acima, tornam o futebol:

(...) popular no Brasil porque ele permite expressar uma série de problemas nacionais, alternando percepção e elaboração intelectual com emoções e sentimentos concretamente sentidos e vividos (DaMATTA, 1982, p.40).

Os termos: "empolgante", "saudade", "sofrido", "emocionar", "chorar", "vergonha", "decepcionante", "triste", "pranto" revelam algumas das emoções sentidas e vivenciadas pelos 
torcedores, sendo que algumas delas fazem parte da listagem de termos relacionados à antropologia das emoções. Quando analisados conjuntamente, esses termos tornam-se antagônicos entre si, pois se referem a Copas com resultados opostos (Pentacampeão e derrota por 7 gols a 1). Além disso, a situação dramática de alguns depoimentos coloca em foco, características da especificidade do futebol brasileiro, sugerindo possíveis dilemas vivenciados por esta sociedade.

Segundo DaMatta(1982, p.32) o destino desse drama social perpassa por escolhas conflituosas "vontades individuais versus força coletiva impessoal". Vale relembrar que o time de 2002 era uma equipe com várias estrelas, mas tratada como um sujeito coletivo. Enquanto o time de 2014 estava alicerçado em um sujeito individual, que partida antes havia sido lesionado gravemente. $O$ futebol reflete a seu tempo como uma sociedade, inclusive a brasileira, elabora a história social de um evento, na qual muitas vezes a expressão individual transcende a expressão da coletividade.

Sahlins(2006) acrescenta outra perspectiva a essa discussão, a da ação histórica que coloca em questão as condições situacionais e organizacionais dos sujeitos históricos (individuais e coletivos) em provocar mudanças. Ao citar do beisebol, as vitórias singulares dos Yankees em 1939 e dos Giants em 1951, mostra que a primeira equipe trilhou conquistas graduais e paulatinas atreladas a um desempenho de longo prazo e de ação sistêmica, tendo como desfecho final a vitória de um sujeito coletivo, o time. E a outra equipe, o triunfo veio de forma individualizada, inusitada e imprevisível a partir do feito de um jogador. Embora sejam diferentes, ambos os eventos ganharam potência simbólica. Embora o risco de uma derrota dos Giants fosse representativa. No caso brasileiro, os depoimentos D1 e D9 assemelham-se as narrativas encontradas em Sahlins (2006), dos Yankees e Giants, respectivamente; bem como ganharam potência simbólica encontrada nas falas dos depoentes 1 e 9. O que contrasta é a fragilidade de um time sem "aquele que faz a diferença".

Interessante destacar as diferentes formas de torcer que os depoimentos mostram. DaMatta (2003) significa o "torcer" para além da definição de filiação a um clube. Para ele, o "torcer" pode ser traduzido como: modos de relacionamento e de simpatia, carregados de símbolos, emblemas e "cores dos times", uma forma de agregar e ser agregado. Ainda para o estudioso, esse pertencer (esportivo) ou "ser parte de" e "se identificar com" não está necessariamente interligado com a distinção social.

No caso deste estudo, os depoimentos utilizados vieram de várias partes do Brasil, são de ambos os gêneros e também de pessoas com profissões bastante diferenciadas, o que pode ser verificado ao acessar os portais já mencionados de onde a pesquisa foi feita. O futebol une uma torcida múltipla e de características diversas, faixa etária, gênero, classe social, localização geográfica, entre outros. E conforme DaMatta(2003) possibilita que essas pessoas confiem que o país representado pelo time possa ser viável, mundialmente excelente e respeitado. E referindo-se as equipes anteriores a 2002, DaMatta(2003, p.20) aponta que essa motivação foi gerada pelos "humildes jogadores de futebol que conquistaram para nós esses campeonatos do mundo". E não por banqueiros, industriais ou políticos.

Nos depoimentos sobre a Copa de 2014, destaca-se o Depoimento D12, que faz um paralelo entre a situação do país e o resultado final do certame:

(...)A cada quatro anos, nós apostamos num futuro maior para a nossa nação. Só que nós esquecemos que temos que trabalhar que nem a Alemanha trabalha, com seriedade, disciplina, e trabalho. A gente acha que em determinado momento Deus vai olhar pra nós e falar que nós somos os melhores do mundo, mas nós não somos. Se nós não tivermos a disciplina, o trabalho e a vontade que a Alemanha, que vai ser campeã, mostrou, nós não 
vamos chegar em lugar nenhum. Chegou a hora de a gente fazer uma mudança que essa nação precisa.

Especialmente essa fala do D12 corrobora o que DaMatta $(1983,2003)$ e Sahlins (2006) denominam como drama social, o jogo como um modelo reduzido da sociedade e de seus valores, expressos através de seus atores, regras e ideologias. Ao comparar a forma com que o time brasileiro joga ao modelo de jogo da equipe alemã, D 12 aponta nesses atores, valores e regras como seriedade, disciplina, trabalho (árduo com objetivo) e vontade, criticando o ideário do acaso divino.

\section{CONCLUSÃO}

Esse estudo possibilitou investigar alguns dos sentimentos coletivos e atemporais, de emoção ou de comoção, ao se tratar de vitória e derrota, que foram manifestados por torcedores brasileiros durante as Copas de 2002 e 2014. Aparece nos depoimentos a discussão entre vontades individuais e coletivas e a ação de sujeitos individuais e coletivos no momento em que os torcedores elaboram suas narrativas. O torcer que une e identifica um grupo também é uma questão que foi levantada; assim como a significação do jogo como drama vivenciado por uma sociedade com valores, ideologias que o jogo de futebol pode representar.

\section{REFERÊNCIAS}

Andrade CD. Quando é dia de futebol. Campinas: Ed. Cia das Letras; 2014.

Bardin L. Análise de Conteúdo. Lisboa, Portugal: Edições 70, LDA; 2009.

Barfield T. Diccionario de Antropología. México, DF: Siglo XXI Editores; 2000.

DaMatta R ; Flores L ; Guedes SL ; Vogel A. Universo do Futebol: Esporte e Sociedade Brasileira. Rio de Janeiro: Pinakotheke; 1982.

DaMatta R. O esporte e o jogo como formadores de comportamentos sociais. In: Ações socioculturais para a cidadania. 2003: Anais do Seminário Internacional Esporte e Sociedade, 2003, São Paulo: Sesc, 2003. p. 1-8.

Domingos T. Encontro de dirigentes na América Central fez a primeira avaliação do torneio disputado no Brasil [Internet]. Rio de Janeiro, Brasil: Portal Goal. 2014. [citado em 2016 Maio. 02]. Disponível em: http://www.goal.com/br/news/227/copa-do mundo/2014/09/12/5101158/confer\%C3\%AAncia-da-fifa-elogia-melhor-copa-do-mundo-detodos-os.

Duarte O. Todas As Copas Do Mundo. São Paulo: Ed. MacGraw Hill; 1987.

Franceschini G; Soares L; Almeida PI. Torcedores deixam o Mineirão antes do intervalo após Alemanha abrir goleada [Internet]. 2014. [citado em 2016 Ago. 03]. Disponível em:< http://copadomundo.uol.com.br/noticias/redacao/2014/07/08/torcedores-deixam-o-mineiraoantes-do-intervalo-apos-alemanha-abrir-goleada.htm

Gehringer M. Almanaque dos mundiais: os mais curiosos casos e histórias de 1930 a 2006. São Paulo: Editora Globo; 2010.

Martinez A. Todas as Copas do Mundo. São Paulo: Icone; 2010. 
Portal BBC Brasil.com. O Brasil pentacampeão e a Copa do Mundo de 2002 [Internet]. Fórum. 2002. [citado em 2016 Ago 03]. Disponível em:<

http://www.bbc.com/portuguese/forum/020630_copa2002.shtml

Portal Estadão. Copa no Brasil é a melhor de todos os tempos diz BBC [Internet]. 2014. [citado Mai. 01]. Disponível em: http://esportes.estadao.com.br/noticias/futebol,copa-do-mundo,copano-brasil-e-a-melhor-de-todos-os-tempos-diz-bbc,1528544

Portal Folha online. Ex-técnicos e jogadores atacam dirigentes e elogiam Ronaldo e Scolari. [Internet]. 2002. [citado Ago. 03]. Disponível em:

http://www1.folha.uol.com.br/folha/esporte/ult92u43992.shtml

Portal G1. Torcedores por todo o país lamentam derrota da Seleção [Internet]. 2014. [citado Ago. 03]. Disponível em: http://g1.globo.com/mundo/blog/o-dia-na-copa/post/torcedores-por-todo-opais-lamentam-derrota-da-selecao.html

Portal Uol tv e famosos. Cazarré elege Copa de 2002 como inesquecível [Internet]. 2002. [citado Ago. 03]. Disponível em http://celebridades.uol.com.br/noticias/redacao/2014/06/25/cazarreelege-copa-de-2002-como-inesquecivel-fui-receber-a-selecao.htm

Ribas LV. O Mundo das Copas. São Paulo: Lua de Papel; 2010.

Sahlins M. História e cultura: apologias a Tucídides. Rio de Janeiro: Jorge Zahar; 2006.

Youtube. Globo Esporte: Memórias do Penta 2002 na Coreia do Sul e no Japão [Internet]. 2010. . [citado Ago. 03]. Disponível em: https://www.youtube.com/watch?v=9vz7szoFHD8 